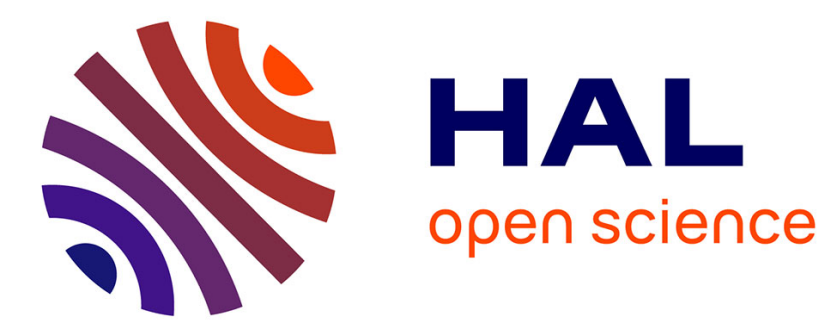

\title{
ROTATIONAL ANALYSIS OF THE MOLECULAR HYDROGEN TRIPLET 3s,d COMPLEX REVISITED
}

Denise Bailly, Michel Vervloet

\section{To cite this version:}

Denise Bailly, Michel Vervloet. ROTATIONAL ANALYSIS OF THE MOLECULAR HYDROGEN TRIPLET 3s,d COMPLEX REVISITED. Molecular Physics, 2007, 105 (11-12), pp.1559-1564. 10.1080/00268970701308448 . hal-00513091

\section{HAL Id: hal-00513091 \\ https://hal.science/hal-00513091}

Submitted on 1 Sep 2010

HAL is a multi-disciplinary open access archive for the deposit and dissemination of scientific research documents, whether they are published or not. The documents may come from teaching and research institutions in France or abroad, or from public or private research centers.
L'archive ouverte pluridisciplinaire HAL, est destinée au dépôt et à la diffusion de documents scientifiques de niveau recherche, publiés ou non, émanant des établissements d'enseignement et de recherche français ou étrangers, des laboratoires publics ou privés. 


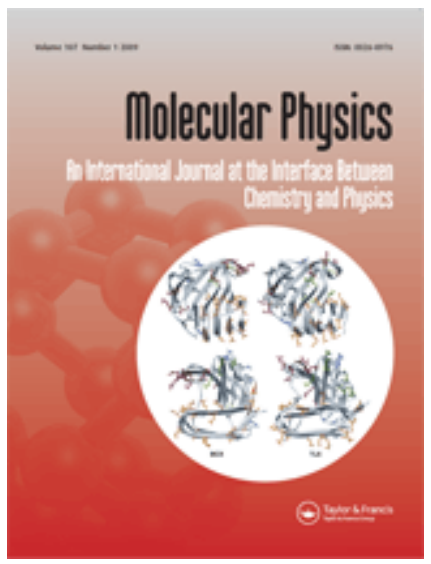

\section{ROTATIONAL ANALYSIS OF THE MOLECULAR HYDROGEN TRIPLET 3s,d COMPLEX REVISITED}

\begin{tabular}{|r|l|}
\hline Journal: & Molecular Physics \\
\hline Manuscript ID: & TMPH-2007-0042.R1 \\
\hline Manuscript Type: & Full Paper \\
\hline Date Submitted by the \\
Author: & $28-$ Feb-2007 \\
\hline Complete List of Authors: & $\begin{array}{l}\text { Bailly, Denise; CNRS, Universite Paris Sud } \\
\text { Vervloet, Michel; Synchrotron SOLEIL }\end{array}$ \\
\hline Keywords: & $\begin{array}{l}\text { H2, 3s,d complex, observed vibronic energies, emission FT } \\
\text { spectrum }\end{array}$ \\
\hline
\end{tabular}

\section{S ScholaroNE" \\ Manuscript Central}




\title{
ROTATIONAL ANALYSIS OF THE MOLECULAR HYDROGEN TRIPLET 3s, $d$ COMPLEX REVISITED
}

\author{
D. BAILLY*† and M. VERVLOET $\ddagger$ \\ † Laboratoire de Photophysique Moléculaire, Université de Paris-Sud, Bât 350 \\ 91405 Orsay Cedex, France \\ Tel : 33-1-69157536 Fax: 33-1-69157530 \\ E-mail: denise.bailly@ppm.u-psud.fr \\ ‡ Synchrotron SOLEIL, L’orme des Merisiers, Saint-Aubin BP 48 \\ 91192 Gif-sur-Yvette, France \\ Tel : 33-1- 69359743 Fax: 33-1-69359456 \\ E-mail: michel.vervloet@ synchrotron-soleil.fr
}




\begin{abstract}
The emission spectrum of neutral diatomic hydrogen has been recorded at Doppler width limited resolution by Fourier transform spectroscopy in the spectral range 1800 $22500 \mathrm{~cm}^{-1}$. Rotational analysis of the triplet systems involving the electronic states $c^{3} \Pi_{u}, a^{3} \Sigma_{g}^{+}, e^{3} \Sigma_{u}^{+}$, and the $3 s, d$ complex has been carried out in order to determine precise rovibronic energies (with $\mathrm{v}=0$ to 3 ) of the $3 s, d$ complex. This new observation agrees with the earlier calculations $[3,4,5]$ within a few $\mathrm{cm}^{-1}$ and corrects incorrect "observed" level energies published for $\mathrm{v}=2$ and $3, h(3 s)^{3} \Sigma_{g}^{+}$in [1,2] and [2] by about 50 and $90 \mathrm{~cm}^{-1}$ respectively.
\end{abstract}

Keywords: $\mathrm{H}_{2} ; 3 s, d$ complex; observed vibronic energies; emission FT spectrum 


\section{INTRODUCTION}

The neutral diatomic hydrogen is the simplest molecule after $\mathrm{H}_{2}^{+}$and the most abundant molecular species in the Universe. Since the beginning of the molecular spectroscopy, it has been the subject of numerous theoretical and experimental studies. Because of the considerable interest of this molecule, Crosswhite edited the well-known hydrogen molecule wavelength tables of G. H. Dieke [1]. Despite the extensive and comprehensive work carried out on this spectrum, a rather large number of lines of significant intensity remain unassigned. This emission spectrum was recorded in the visible and near infrared region by means of photographic plate spectrographs and scanning monochromators respectively. Nowadays, we can record the emission spectrum by using Fourier Transform (FT) spectrometers in the two spectral ranges, hopefully with a better frequency calibration and an improved sensitivity in the near infrared and infrared domains. In the visible region, we notice, as expected, a clear correspondence between the frequencies and the intensities of the Dieke tables and those of a FT spectrum. However, the similarity between the two spectra is surprisingly not so clear in the near infrared, as shown in figure 1 . Because of the importance of diatomic hydrogen, we have decided to try to reduce the number of unassigned lines by analysing in detail a new high resolution emission spectrum that we have recorded by FT spectroscopy and covering the wide spectral range $1800-22500 \mathrm{~cm}^{-1}$. The emission spectrum is composed of singlet and triplet systems which have been analysed by several authors and the level energy structure have been understood with different types of theoretical approaches. The agreement between the observations and the calculations resulting from them is generally satisfactory, of the order of a few $\mathrm{cm}^{-1}$, with the 
exception of some levels of the triplet $3 s, 3 d$ complex. This complex is composed of four close lying components, namely the $h(3 s)^{3} \Sigma_{g}^{+}, g(3 d)^{3} \Sigma_{g}^{+}, \quad i(3 d)^{3} \Pi_{g}$, and $j(3 d)^{3} \Delta_{g}$ states. Their rovibronic structure have been analysed from emission spectra by Dieke [1] and Alikacem and Larzillière [2]. Nonadiabatic calculations have been performed on the $3 s, 3 d$ complex by Schins et al. [3] who fitted the coupling functions to experimental data. Ross and Jungen [4] applied multichannel quantum-defect theory (MQDT) to calculate singlet and triplet gerade $n=2$ and 3 rovibronic energies using quantum defect functions extracted from ab initio potential energy functions available in the literature. More recently, Pazyuk et al. revisited the $f$-symmetry components of the $3 s, 3 d$ complex with non adiabatic calculations using coupling and other functions derived from a modified MQDT approach [5]. A strong disagreement of the order of 50 and $90 \mathrm{~cm}^{-1}$ occurs for all the observed rotational levels of $\mathrm{v}=2$ (reported in [1,2]) and $\mathrm{v}=3$ (reported in [2]) of $h(3 s)^{3} \Sigma_{g}^{+}$respectively, between the observed and the calculated level energies $[3,4,5]$. The authors of $[3,4,5]$ have deduced that all the levels of $\mathrm{v}=2$ and 3 of $h(3 s)^{3} \Sigma_{g}^{+}$have been misassigned in [1,2] and [2] respectively.

The main goal of this paper is to clarify this point of disagreement between the published observations [1,2] and the calculated rovibronic level energies in $\mathrm{v}=2$ and 3 of $h(3 s)^{3} \Sigma_{g}^{+}$. We aim also that our analysis will improve the accuracy of all the observed level energies of the $3 s, d$ complex previously reported in the literature. '[Insert Fig1 about here]'

\section{EXPERIMENTAL}


Excited diatomic $\mathrm{H}_{2}$ was produced by flowing hydrogen through a microwave discharge. The emission chamber was a quartz tube (diameter: $1 \mathrm{~cm}$, length: $25 \mathrm{~cm}$ ). The pressure and the flow rate of hydrogen together with the power of microwave power supply were adjusted in order to obtain maximum intensity of molecular hydrogen and minimum emission of atomic lines. With our set-up, the experimental parameters were about 5 mbar by using a $20 \mathrm{~m}^{3} / \mathrm{h}$ mechanical vacuum pumping and a $70 \mathrm{~W}$ microwave power. The light of the discharge was focussed onto the entrance iris of a FT spectrometer (Bruker IFS 120). The emission spectrum was recorded from 1800 to $22500 \mathrm{~cm}^{-1}$ by using appropriate optical filters and detectors which were a liquid nitrogen cooled InSb photodiode $\left(1800-6500 \mathrm{~cm}^{-1}\right.$, equipped with a cold short wavelength pass interference filter for the range $3300-6500 \mathrm{~cm}^{-1}$ ), a liquid nitrogen cooled InGaAs photodiode (6500 - $\left.9000 \mathrm{~cm}^{-1}\right)$, an avalanche silicon photodiode (9000 $\left.17000 \mathrm{~cm}^{-1}\right)$ and a photomultiplier $\left(17000-22500 \mathrm{~cm}^{-1}\right)$. The spectrum was recorded at Doppler width limited resolution which varied from about $0.02 \mathrm{~cm}^{-1}$ (infrared) to 0.2 $\mathrm{cm}^{-1}$ (violet). When necessary, several measurements were made and co-added for some spectral ranges in order to increase the signal-to-noise ratio up to a satisfactory level. Traces of $\mathrm{CO}$ and Ar, for which the line frequencies are reported in [6] and [7] respectively, were added to the hydrogen flow for calibration purposes.

\section{OBSERVED TRANSITIONS}

The electronic transitions analysed in this work are illustrated in figure 2. The four electronic states which form the $3 s, d$ complex allow visible transitions with the lowest 
$c^{3} \Pi_{u}^{+}$state. Four other transitions, namely $i-e, g-e, h-e$ and $e-a$, occur in the near infrared, while the lines of $a-c$ are observed in the infrared region.

'[insert Fig. 2 about here]'

The $a^{3} \Sigma_{g}^{+}-c^{3} \Pi_{u}$ transition has been studied by Dabrowski and Herzberg [8]. The component $c^{3} \Pi_{u}^{+}$of the $c$ state is strongly predissociated by the repulsive $b^{3} \Sigma_{u}^{+}$ state which correlates with the two hydrogen atoms in their ground state. This predissociation can cause an inverted population in an electric discharge in hydrogen and can generate infrared laser emission as first observed by McKnight and Barr [9, 10]. As a consequence of this predissociation, only the transitions involving $c^{3} \Pi_{u}^{-}$can be observed in our emission spectrum. The $a-c$ bands show P, Q and R branches while the $c$ - $a$ bands exhibit only one Q branch. Moreover, the spin-orbit interaction weakly predissociates the levels of $c^{3} \Pi_{u}^{-}$and has the effect of increasing the width of the $\mathrm{P}$ and $\mathrm{R}$ lines in the emission $a-c$. Figure 3 a shows a region where the $\mathrm{Q}$ branch of 1- $0, a-c$ is observed together with $\mathrm{P}(2)$ of $4-2,3-4$, and $7-6$. The width of the $\mathrm{P}$ and $\mathrm{R}$ lines increases as the vibrational number $\mathrm{v}$ rises. This behaviour is represented on Figure $3 \mathrm{~b}$ for the P (2) lines. The Q lines are composed of two components, splitted by about 0.15 $\mathrm{cm}^{-1}$, as can be seen on figure $3 \mathrm{a}$. This splitting results from the fine structure of the rotational levels of $c^{3} \Pi_{u}^{-}$which has been observed directly in para and orthohydrogen by Lichten and co-workers $[11,12]$ using a magnetic resonance technique. It can be deduced from [11] that the weaker components observed in the Q doublet lines involve the $F_{2}$ spin component of their lower rotational level while the stronger component is actually composed of two overlapped lines involving the $F_{1}$ and $F_{3}$ spin components of their lower levels. In the spectral range that we have recorded, we observe the sequence 
$\Delta \mathrm{v}=+1$ of $a-c$ from $\mathrm{v}^{\prime}=1$ to $\mathrm{v}^{\prime}=7$. The system $c^{3} \Pi_{u}^{+}-a^{3} \Sigma_{g}^{+}$, exhibiting $\mathrm{Q}$ branches only, is also observed through its sequences $\Delta v=+1,+2$ and +3 with $v^{\prime}{ }_{\text {max }}=2$, 4 and 4 respectively.

The system $e^{3} \Sigma_{u}^{+}-a^{3} \Sigma_{g}^{+}$is relatively intense and occurs in the near infrared region. The bands, composed of $\mathrm{P}$ and $\mathrm{R}$ lines which do not show any fine structure splitting, belong to the sequences $\Delta v=0,+1$ and +2 . In this system, the vibrational levels of $e$ and $a$ are observed from 0 to 5.

The $h(3 s)^{3} \Sigma_{g}^{+}, g(3 d)^{3} \Sigma_{g}^{+}, i(3 d)^{3} \Pi_{g}$, and $j(3 d)^{3} \Delta_{g}$ states form the socalled $3 s, d^{3} \Delta_{g}$ complex. The electronic energies of these four states cover a range smaller than $800 \mathrm{~cm}^{-1}$. This situation causes the breakdown of the Born-Oppenheimer approximation and the L-uncoupling effect. The ${ }^{3} \Pi_{\mathrm{g}}$ and ${ }^{3} \Delta_{\mathrm{g}}$ states are each composed of two half-states ${ }^{3} \Pi_{g}^{+}$and ${ }^{3} \Pi_{g}^{-}$, and ${ }^{3} \Delta_{g}^{+}$and ${ }^{3} \Delta_{g}^{-}$respectively. The states of same parity interact and give a complicated energy structure. Calculations of different approach $[3,4,5,13]$ have been carried out on the $3 s, d^{3} \Delta_{\mathrm{g}}$ complex for each parity, taking into account the $\lambda$-doubling. They agree with the observations, excepted, as already mentioned, for $\mathrm{v}=2$ and 3 of $h(3 s)^{3} \Sigma_{g}^{+}$. The levels of $\mathrm{v}=0,1,2$, and 3 of $h, g$, $i$, and $j$ have transitions with $c^{3} \Pi_{\mathrm{u}}$. The transitions $h-c$ and $g-c$, do not show broad P and $\mathrm{R}$ lines, nor do they have doublet $\mathrm{Q}$ lines, as in the $a-c$ transition (see Figure 3a), because the Doppler width of their components (about $0.2 \mathrm{~cm}^{-1}$ in the visible region) is larger than their splitting. However, the $\mathrm{Q}$ lines exhibit a slight asymmetric profile degraded, as expected, towards the low frequencies and resulting from the fine structure of the $c$ state. The same asymmetric profile is also observed in the $\mathrm{Q}$ lines of $i^{3} \Pi_{g}^{+}-$ $c^{3} \Pi_{u}^{-}$and $j^{3} \Delta_{g}^{+}-c^{3} \Pi_{u}^{-}$, and in the $\mathrm{P}$ and $\mathrm{R}$ lines emitted from $i^{3} \Pi_{g}^{-}$and $j^{3} \Delta_{g}^{-}$since 
they involve the same group of lower rotational levels of $c^{3} \Pi_{u}^{-}$. This distinctive feature has been used for line identification during the course of the analysis of the visible spectrum.

'[insert Fig 3 about here]'

\section{DETERMINATION OF THE OBSERVED LEVEL ENERGIES}

The determination of the level energies has been carried out by using the observed combination differences. The energy origins for triplet para and orthohydrogen has been taken to their values determined in [14], that is $95076.298 \mathrm{~cm}^{-1}$ and $95142.982 \mathrm{~cm}^{-1}$ for $\mathrm{N}=0$ and $1, a^{3} \Sigma_{g}^{+}, \mathrm{v}=0$ respectively. The rovibronic energies have been determined by adding and subtracting the weighted arithmetic means of the observed combination differences to previous energies obtained by the same way. This process started from the energies of $\mathrm{N}=0$ and 1 of $a^{3} \Sigma_{g}^{+}, \mathrm{v}=0$. In this way we have been able to build a precise set of observed rovibronic energies for the levels involved in this analysis. Line frequencies of the analysed bands are available on request from the authors. The level energies of the $3 s, d$ complex are reported in table 1 . The relative precision of the energies varies for each level. However, we believe that the averaged relative precision is better than $0.01 \mathrm{~cm}^{-1}$.

'[insert Table 1 about here]'

\section{DISCUSSION}

The three columns "o - c" of table I show the differences between the observed energies resulting from the analysis of this work and the calculated energies of [3], [4] and [5] 
obtained with different calculation approaches. It can be seen that there is a good agreement between our observations and the calculations, in particular for the observed rovibronic energies of $\mathrm{v}=2$ and 3 of $h(3 s)^{3} \Sigma_{g}^{+}$which show respectively "o - c" 's of about $-50 \mathrm{~cm}^{-1}$ and $-90 \mathrm{~cm}^{-1}$ in $[3,4,5]$. The strongest discrepancy $\left(+16.2 \mathrm{~cm}^{-1}\right)$ occurs for the level $\mathrm{N}=5$ of $\mathrm{v}=2, h(3 s)^{3} \Sigma_{g}^{+}$with the calculated energies of [4] resulting from $a b$ initio MQDT calculations. However, the " $\mathrm{o}-\mathrm{c}$ " 's are smaller for the levels of $\mathrm{v}=$ 3, $h(3 s)^{3} \Sigma_{g}^{+}$, thus demonstrating the high quality of the MQDT calculations reported in [4]. We have determined the levels of $\mathrm{v}=2$ and 3 of $h(3 s)^{3} \Sigma_{g}^{+}$by analysing the bands $2-1,2-2,2-3$, and $3-2,3-3$ and $3-4$ of the system $h^{3} \Sigma_{g}^{+}-e^{3} \Sigma_{u}^{+}$. This system occurs in the near infrared region. The narrower line Doppler width, compared to the visible one, the precise rovibronic energies of the $e^{3} \Sigma_{u}^{+}$state, that we determine from the near infrared transition $e^{3} \Sigma_{u}^{+}-a^{3} \Sigma_{g}^{+}$, and the rotational analysis carried out on six bands guaranty a correct determination of the level energies of $\mathrm{v}=2$ and 3 of $h(3 s)^{3} \Sigma_{g}^{+}$. Our assignment work has been highly facilitated by the previous analysis of Dieke [1], Alikacem and Larzillière [2], and of Jungen et al. [14], and also by the calculations $[3,4,5]$ used in columns "o - c" of table 1 . We succeeded in the analysis of $h, \mathrm{v}=2$ and 3 thanks to the relatively strong spectrum intensity, in our experimental condition, of the near infrared transition $h-e$. Unfortunately, the published calculations $[3,4,5]$ concern only the four first vibrational levels of the complex and do not give any help in the search of new assignments of $\mathrm{v}=4$ levels. However, de Bruijn and Helm [15] measured dissociative decay times of $n=3$ levels of $\mathrm{H}_{2}$ by using fast neutral-beam photofragment spectroscopy. They have been able to observe new transitions from the 
metastable $c^{3} \Pi_{u}^{-}$state to dissociative triplet gerade levels of the $3 s, d$ complex. They tentatively assigned a signal observed at $16802 \mathrm{~cm}^{-1}$ (table I of [15]) to the transitions $\mathrm{Q}(1)$ and $\mathrm{Q}(3)$ of the band $3-3, h-c$. Our analysis does not agree with their tentative assignments since these transitions are present in our spectrum at 16824.73 and $16822.55 \mathrm{~cm}^{-1}$ respectively. They also determined $\mathrm{Q}(1)$ and $\mathrm{Q}(3)$ of the band $4-4$ of the same electronic transition to be at 16729 and $16731 \mathrm{~cm}^{-1}$ respectively. We have not seen any line supporting these assignments in the visible transition $h-c$ of our spectrum, nor in the more intense near infrared system $h^{3} \Sigma_{g}^{+}-e^{3} \Sigma_{u}^{+}$where the search of the band 4 - 4 remained unsuccessful during our analysis work. We believe that this lack of intensity is due to the predissociation of $h$. We have tried to assign some transitions involving $\mathrm{v}=4$ of the $i$ and $j$ states by using the measurements reported in [15]. So far, our attempts have also been unsuccessful.

\section{CONCLUSION}

We have drawn up a set of precise rovibronic energies for the four first vibrational levels of the triplet $3 s, d$ complex of hydrogen. This has been performed by analysing a high signal-to-noise ratio emission FT spectrum of $\mathrm{H}_{2}$ recorded at Doppler limited resolution in the spectral range $1800-22500 \mathrm{~cm}^{-1}$. The high precision of near infrared and infrared transition frequencies have strongly contributed to high accuracy in the determination of the rovibronic energies. The analysis has been much made easier thanks to the impressive work of Dieke [1] and to the precise calculations of Shins et al. [3], Ross and Jungen [4], and Pazyuk et al. [5]. We have corrected the wrong assignments given in the literature $[1,2]$ for $\mathrm{v}=2$ and 3 of $h^{3} \Sigma_{g}^{+}$. Our new observed 
values agree with the previously calculated ones $[3,4,5]$. We hope that our new set of data will be useful in future theoretical calculations.

\section{ACKNOWLEDGMENTS}

We thank Dr Ch. Jungen and Professor S. C. Ross for having pointed out this problem to our attention, and for the encouragement they have provided to us for reconsidering the rotational analysis of the hydrogen emission spectrum. We also thank the French research program P. C. M. I. for partial financial support. 


\section{REFERENCES}

[1] H. M. Crosswhite (Ed). The Hydrogen Molecule Wavelength Tables of G. H. Dieke Wiley, New York, (1972)

[2] A. Alikacem, M. Larzillière, J. Chem. Phys., 93, 215 (1990).

[3] J. M. Schins, L. D. A. Siebbeles, J. Los, W. J. van der Zande, Phys. Rev. A, 44, 4162 (1991)

[4] S. C. Ross, Ch Jungen, Phys. Rev. A, 50, 4618 (1994)

[5] E. A. Pazyuk, V. I. Pupyshev, A. V. Stolyarov, T. Kiyoshima, J. Chem. Phys., 116, $6618(2002)$

[6] A.G. Maki , J.S. Wells, D. A. Jennings J. Mol Spectrosc; 144, 224 (1990)

[7] G. Norlén, Phys. Scr. 8, 249 (1973)

[8] I. Dabrowski, G. Herzberg, Acta Phys. Hung., 55, 219 (1984)

[9] W. B. McKnight, T. A. Barr, Jr., Appl. Opt., 21, 357, (1982)

[10] T. A. Barr, Jr., W. B. McKnight, Appl. Phys. Lett., 41, 114 (1982)

[11] P. R. Brooks, W. Lichten, R. Reno, Phys. Rev. A, 4, 2217 (1971)

[12] W. Lichten, T. Wik, J. Chem. Phys., 69, 5428 (1978)

[13]C. B. Wakefield, E. R. Davidson, J. Chem. Phys., 43, 834 (1965)

[14] Ch. Jungen, I. Dabrowski, G. Herzberg, M. Vervloet, J. Chem. Phys., 93, 2289 (1990)

[15] D. P. de Bruijn, H. Helm, Phys. Rev. A, 34, 3855 (1986) 
Figure 1 


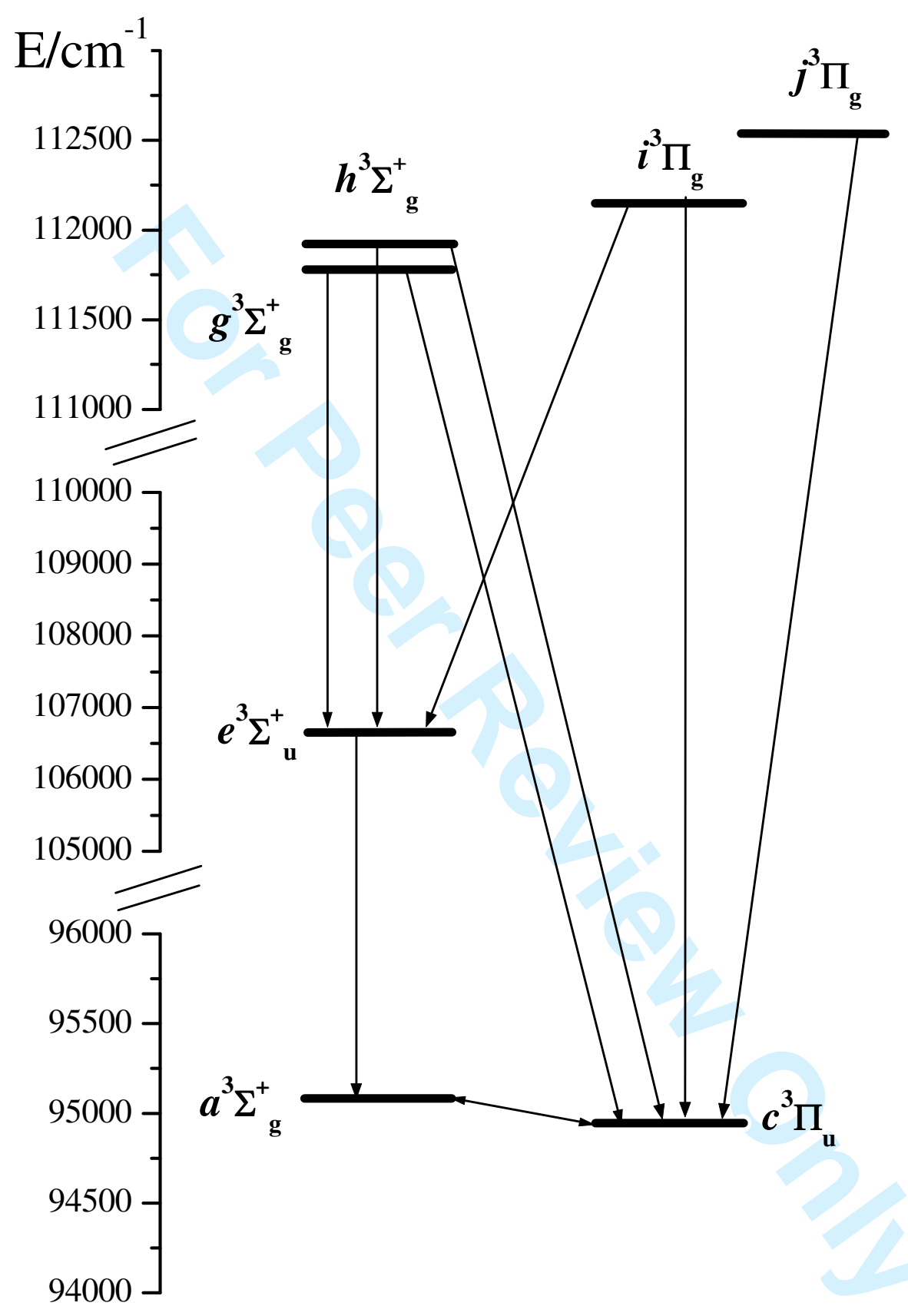

Figure 2 


$$
a^{3} \Sigma_{g}^{+} \rightarrow c^{3} \Pi_{u}
$$

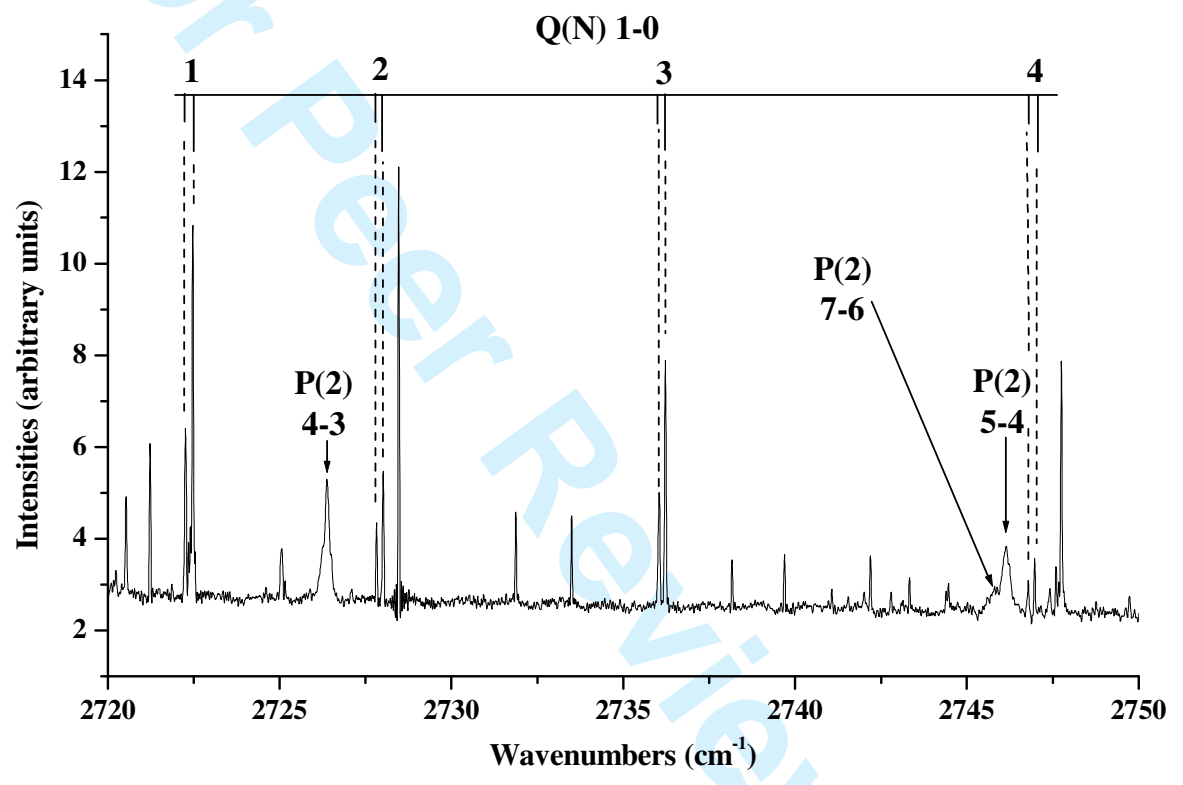

Figure $3 \mathrm{a}$ 


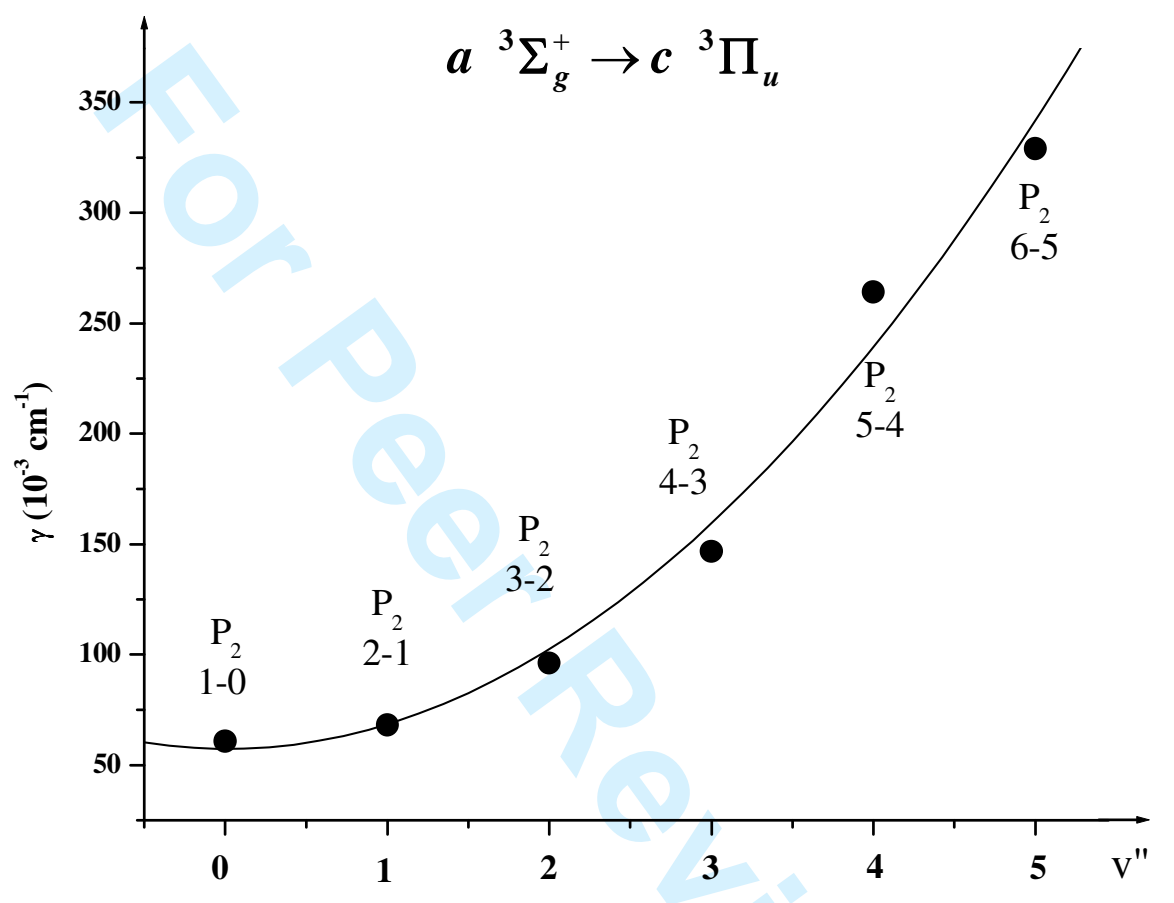

Figure $3 b$ 
TABLE 1: Comparison of the observed and calculated energy levels of ref [3,4,5] for the hydrogen $n=3$ triplet gerade complex; all the energies are given in $\mathrm{cm}^{-1}$ relative to the $\mathrm{J}=0, \mathrm{v}=0$ level of the $X^{1} \Sigma_{g}^{+}$ground state

\begin{tabular}{|c|c|c|c|c|c|c|c|c|c|}
\hline v N & Observed & $\begin{array}{c}\mathrm{O}-\mathrm{C} \\
\operatorname{Ref}(5)\end{array}$ & $\begin{array}{c}\text { O-C } \\
\operatorname{Ref}(4)\end{array}$ & $\begin{array}{c}\mathrm{O}-\mathrm{C} \\
\operatorname{Ref}(3) \\
\end{array}$ & $\mathrm{v} \mathrm{N}$ & Observed & $\begin{array}{c}\mathrm{O}-\mathrm{C} \\
\operatorname{Ref}(5) \\
\end{array}$ & $\begin{array}{c}\mathrm{O}-\mathrm{C} \\
\operatorname{Ref}(4) \\
\end{array}$ & $\begin{array}{c}\mathrm{O}-\mathrm{C} \\
\operatorname{Ref}(3) \\
\end{array}$ \\
\hline \multicolumn{5}{|c|}{$g^{3} \Sigma_{g}^{+}$} & \multicolumn{5}{|c|}{$h^{3} \Sigma_{g}^{+}$} \\
\hline 00 & 111783.17 & -0.34 & -7.2 & -0.12 & 00 & 111932.55 & 0.57 & 6.2 & -2.19 \\
\hline 01 & 111796.45 & -0.56 & -4.8 & -0.47 & 01 & 111948.14 & 0.96 & 2.0 & -0.20 \\
\hline 02 & 111826.48 & -0.61 & -2.6 & -0.47 & 02 & 112049.97 & 1.02 & -0.8 & +0.38 \\
\hline 03 & 111896.62 & -0.57 & -1.6 & -0.18 & 03 & 112223.27 & 1.02 & -2.1 & +0.53 \\
\hline 04 & 112017.20 & -0.57 & -1.1 & & 04 & 112458.17 & 1.00 & -2.8 & \\
\hline 05 & 112190.74 & -0.57 & -0.9 & & 04 & 112750.49 & 0.99 & & \\
\hline 06 & 112417.14 & -0.59 & & & 06 & 113097.20 & & & \\
\hline 07 & 112695.26 & -0.59 & & & 07 & 113495.47 & & & \\
\hline 10 & 113883.11 & -2.23 & -8.7 & 0.09 & 10 & 114179.27 & 0.28 & 8.3 & -0.00 \\
\hline 11 & 113883.65 & -1.76 & -5.7 & -0.03 & 11 & 114197.96 & -1.44 & -7.3 & +0.44 \\
\hline 12 & 113910.93 & -1.43 & -3.5 & -0.20 & 12 & 114312.07 & -1.87 & -9.4 & +0.30 \\
\hline 13 & 113980.34 & -1.22 & -2.2 & -0.36 & 13 & 114482.27 & -2.08 & -10.6 & +0.07 \\
\hline 14 & 114097.39 & -1.13 & -1.5 & & 14 & 114707.01 & -2.28 & -11.7 & \\
\hline 15 & 114263.79 & -1.07 & -1.0 & & 15 & 114984.45 & -2.50 & -12.9 & \\
\hline 16 & 114481.95 & +1.43 & & & 16 & 115312.20 & -2.82 & & \\
\hline 17 & 114743.40 & -1.16 & & & 17 & 115687.50 & -3.23 & & \\
\hline 20 & 115785.01 & -3.57 & -6.4 & -0.29 & 20 & 116333.49 & -0.65 & +6.5 & +2.38 \\
\hline 21 & 115794.44 & -3.15 & -4.9 & -0.24 & 21 & 116389.89 & -0.24 & +7.9 & +2.55 \\
\hline 22 & 115829.39 & -2.67 & -3.4 & -0.19 & 22 & 116501.86 & 0.50 & +10.2 & +2.89 \\
\hline 23 & 115901.96 & -2.28 & -2.3 & -0.16 & 23 & 116667.64 & 1.43 & +12.9 & +3.38 \\
\hline 24 & 116017.47 & -2.18 & -1.7 & & 24 & 116884.61 & 2.27 & +15.1 & \\
\hline 25 & 116178.50 & -1.83 & -1.0 & & 25 & 117150.16 & 2.90 & +16.2 & \\
\hline & & & & & 26 & 117462.08 & & & \\
\hline 30 & 117508.48 & -5.67 & & -0.12 & 30 & 118368.04 & -0.91 & +4.9 & +8.47 \\
\hline 31 & 117527.20 & -5.00 & & 0.43 & 31 & 118419.96 & & +5.1 & +8.61 \\
\hline 32 & 117571.50 & -4.49 & & 0.80 & 32 & 118523.25 & & +5.5 & +8.88 \\
\hline 33 & 117649.44 & -4.01 & & 1.15 & 33 & 118676.92 & & +5.9 & +9.28 \\
\hline 34 & 117765.88 & -3.63 & & & 34 & 118879.48 & & & \\
\hline 35 & 117923.34 & -3.31 & & & 35 & 119129.12 & & & \\
\hline
\end{tabular}


TABLE 1: continued

\begin{tabular}{|c|c|c|c|c|c|c|c|c|c|}
\hline v N & Observed & $\begin{array}{c}\mathrm{O}-\mathrm{C} \\
\operatorname{Ref}(5) \\
\end{array}$ & $\begin{array}{c}\text { O-C } \\
\operatorname{Ref}(4) \\
\end{array}$ & $\begin{array}{c}\text { O-C } \\
\operatorname{Ref}(3) \\
\end{array}$ & v N & Observed & $\begin{array}{c}\text { O-C } \\
\operatorname{Ref}(5)\end{array}$ & $\begin{array}{c}\text { O-C } \\
\operatorname{Ref}(4) \\
\end{array}$ & $\begin{array}{c}\text { O-C } \\
\operatorname{Ref}(3) \\
\end{array}$ \\
\hline \multicolumn{5}{|c|}{$i^{3} \Pi_{g}^{+}$} & \multicolumn{5}{|c|}{$i^{3} \Pi_{g}^{-}$} \\
\hline 01 & 112153.59 & -0.07 & +0.8 & -0.68 & 01 & 112066.57 & & -1.1 & -1.14 \\
\hline 02 & 112310.88 & -0.29 & +0.8 & -1.46 & 02 & 112140.80 & & -1.3 & +0.73 \\
\hline 03 & 112503.66 & -0.45 & +0.4 & -1.93 & 03 & 112264.86 & & -1.5 & +0.50 \\
\hline 04 & 112741.12 & -0.38 & +0.6 & & 04 & 112441.72 & & -1.8 & \\
\hline \multirow{2}{*}{05} & 113027.03 & -0.57 & +0.5 & & 05 & 112671.73 & & -2.0 & \\
\hline & & & & & 06 & 112953.92 & & & \\
\hline 11 & 114269.05 & +0.80 & +11.6 & -0.11 & 11 & 114179.27 & & -0.8 & 0.48 \\
\hline 12 & 114419.34 & +0.86 & +11.1 & -0.15 & 12 & 114258.96 & & -1.1 & +0.20 \\
\hline 13 & 114614.35 & +1.16 & +10.7 & 0.12 & 13 & 114384.32 & & -1.3 & +0.18 \\
\hline 14 & 114850.22 & +0.96 & +10.1 & & 14 & 114557.64 & & -1.6 & \\
\hline 15 & 115129.12 & +1.11 & +10.4 & & 15 & 114779.59 & & -1.8 & \\
\hline 16 & 115451.84 & +1.38 & & & & & & & \\
\hline 21 & 116182.08 & -1.88 & -3.4 & -0.09 & 21 & 116145.66 & & -0.6 & +0.25 \\
\hline 22 & 116319.26 & -2.98 & -7.5 & -0.68 & 22 & 116227.87 & & -0.8 & +0.24 \\
\hline 23 & 116504.15 & -4.10 & -11.7 & -1.43 & 23 & 116353.34 & & -1.0 & +0.20 \\
\hline 24 & 116731.80 & -4.82 & -14.9 & & 24 & 116523.29 & & -1.1 & \\
\hline 25 & 116999.64 & -5.88 & -17.3 & & 25 & 116738.09 & & -1.4 & \\
\hline 26 & 117307.70 & -6.05 & & & & & & & \\
\hline 31 & 117983.53 & -2.37 & & -0.21 & 31 & 117958.81 & & & +0.48 \\
\hline 32 & 118106.80 & -3.09 & & -0.15 & 32 & 118041.02 & & & +0.43 \\
\hline 33 & 118278.76 & -3.80 & & -0.20 & 33 & 118164.87 & & & +0.34 \\
\hline 34 & & $i^{3} \Delta^{+}$ & & & & & $i^{3} \Delta^{-}$ & & \\
\hline 02 & 112529.55 & -0.44 & -1.2 & -0.51 & 02 & 112513.90 & & -1.5 & -0.50 \\
\hline 03 & 112779.37 & -0.35 & -0.5 & -0.68 & 03 & 112732.19 & & -1.1 & -0.45 \\
\hline 04 & 113094.36 & +1.20 & +1.4 & & 04 & 113007.53 & & -0.9 & \\
\hline \multirow[t]{2}{*}{05} & 113460.56 & -0.24 & +0.4 & & 05 & 113336.22 & & -0.6 & \\
\hline & & & & & 06 & 113714.92 & & & \\
\hline 12 & 114711.99 & 0.01 & -0.8 & -0.19 & 12 & 114706.70 & & -0.9 & -0.39 \\
\hline 13 & 114924.57 & -0.05 & -0.1 & -0.13 & 13 & 114904.28 & & -0.9 & -0.73 \\
\hline 14 & 115200.97 & -0.12 & +0.5 & & 14 & 115158.26 & & -0.2 & \\
\hline 15 & 115533.31 & -0.15 & +1.2 & & 15 & 115462.97 & & -0.4 & \\
\hline 22 & 116777.88 & +1.65 & -0.3 & +0.24 & 22 & 116776.12 & & -0.3 & +0.24 \\
\hline 23 & 116962.08 & +1.30 & +0.1 & +0.04 & 23 & 116954.74 & & -0.2 & 0.00 \\
\hline 24 & 117203.78 & +0.89 & +0.7 & & 24 & 117186.32 & & 0.2 & \\
\hline 25 & 117498.59 & +0.56 & +1.3 & & 25 & 117467.08 & & & \\
\hline 32 & 118725.57 & & & -0.50 & 32 & 118725.08 & & & -0.47 \\
\hline 33 & 118885.54 & & & -0.82 & 33 & 118885.19 & & & -0.90 \\
\hline \multirow[t]{2}{*}{34} & 119099.93 & & & & 34 & 119094.02 & & & \\
\hline & & & & & 35 & 119348.13 & & & \\
\hline
\end{tabular}

